ARTICLE

DOI: $10.1038 / \mathrm{s} 41467-017-02543-8$

\title{
Biotransformation of polyunsaturated fatty acids to bioactive hepoxilins and trioxilins by microbial enzymes
}

\author{
Jung-Ung An¹, Yong-Seok Song ${ }^{1}$, Kyoung-Rok Kim¹, Yoon-Joo Ko², Do-Young Yoon ${ }^{1} \&$ Deok-Kun Oh${ }^{1}$
}

\begin{abstract}
Hepoxilins (HXs) and trioxilins ( $\operatorname{Tr} X s)$ are involved in physiological processes such as inflammation, insulin secretion and pain perception in human. They are metabolites of polyunsaturated fatty acids (PUFAs), including arachidonic acid, eicosapentaenoic acid and docosahexaenoic acid, formed by 12-lipoxygenase (LOX) and epoxide hydrolase (EH) expressed by mammalian cells. Here, we identify ten types of HXs and $\operatorname{Tr} X s$, produced by the prokaryote Myxococcus xanthus, of which six types are new, namely, $H X B_{5}, H X D_{3}, H X E_{3}$, $\operatorname{TrXB}_{5}, \operatorname{TrXD}_{3}$ and $\operatorname{TrXE}_{3}$. We succeed in the biotransformation of PUFAs into eight types of HXs ( $>35 \%$ conversion) and $\operatorname{TrXs}$ ( $>10 \%$ conversion) by expressing M. xanthus 12-LOX or 11-LOX with or without EH in Escherichia coli. We determine 11-hydroxy-eicosatetraenoic acid, $\mathrm{HXB}_{3}, \mathrm{HXB}_{4}, \mathrm{HXD}_{3}, \operatorname{TrXB_{3}}$ and $\operatorname{TrXD_{3}}$ as potential peroxisome proliferator-activated receptor- $\gamma$ partial agonists. These findings may facilitate physiological studies and drug development based on lipid mediators.
\end{abstract}

\footnotetext{
${ }^{1}$ Department of Integrative Bioscience and Biotechnology, Konkuk University, 120 Neungdong-ro, Gwangjin-gu, Seoul 05029, Republic of Korea. ${ }^{2}$ National Center for Inter-University Research Facilities (NCIRF), Seoul National University, 1 Gwanak-ro, Gwanak-gu, Seoul 08826, Republic of Korea. Correspondence and requests for materials should be addressed to D.-K.O. (email: deokkun@konkuk.ac.kr)
} 
ipid mediators are signalling transduction molecules essential for homeostasis and intracellular communication in humans. They are C20- and C22-polyunsaturated fatty acids (PUFAs) containing hydroxyl group(s) and/or an epoxide group with or without a C5 ring. Lipid mediators include leukotrienes (LTs), lipoxins (LXs), resolvins (RVs), protectins (PTs), hepoxilins (HXs), trioxilins (TrXs) and prostaglandins (PGs), which are involved in the regulation of the immune and inflammatory responses of humans ${ }^{1}$ (see Supplementary Table 1 for abbreviations). Owing to their anti-inflammatory, anti-infective, antibacterial, anti-viral, anti-apoptotic, neuroprotective and tissuehealing properties, these lipid mediators have attracted much attention in recent years.

HXs and TrXs are C20- and C22-PUFAs, with the former having a hydroxyl group and an epoxide group at C11 and C12, and the latter having three hydroxyl groups. The classification and chemical names of all HXs and TrXs are presented in Supplementary Table 2. They are found in various types of organs, tissues and cells, including brain ${ }^{2}$, aorta ${ }^{3}$, insulinoma ${ }^{4}$, epidermis $^{5}$, platelets ${ }^{6}$ and neutrophils ${ }^{7}$. Compounds of HXA series contain a hydroxyl group at $\mathrm{C} 8$, whereas compounds of $\mathrm{HXB}$ series have a hydroxyl group at $\mathrm{C} 10$. In humans, arachidonic acid (ARA) is metabolized to $\mathrm{HXA}_{3}$ and $\mathrm{HXB}_{3}$ by ARA 12lipoxygenase (LOX), which are converted to $\operatorname{TrXA}_{3}$ and $\operatorname{TrXB}_{3}$ through the hydrolysis of the epoxy group in $\mathrm{HXA}_{3}$ and $\mathrm{HXB}_{3}$, respectively, by $\mathrm{HX}$ epoxide hydrolase $(\mathrm{EH})$ (Supplementary Fig. 1). HXs are involved in insulin secretion ${ }^{8}$, calcium regulation $^{9}$, potassium regulation ${ }^{10}$, platelet aggregation ${ }^{11}$ and vascular permeability $^{12}$. HXs are also chemotactic factors for human neutrophils like $\mathrm{LTs}^{7}$ and pathogen-elicited epithelial chemoattractants $^{13}$. HXs and TrXs regulate vasorelaxation in the arteries ${ }^{14}$, affect the nuclear receptor peroxisome proliferator-activated receptor alpha $(P P A R \alpha)^{15}$ and are involved in regulating the life cycle of barnacles, e.g. in egg hatching and larval settlement ${ }^{16}$. Thus, they are important lipid mediators for various organisms.

LOXs, cyclooxygenases (COXs) and the cytochrome P450 families are the starting enzymes for the biosynthesis of lipid mediators using PUFAs as substrates ${ }^{17}$. Among these enzymes, LOXs, a family of non-heme-iron-containing dioxygenases, catalyse the dioxygenation of PUFAs containing one or more Z,Z1,4-pentadiene structures to hydroperoxy fatty acids (HPFAs). They also catalyse the epoxidation of HPFAs to epoxy hydroxy fatty acids (EHFAs) such as LTs and HXs. LOXs are classified as 5-, 8-, 11-, 12- and 15-LOXs according to the number of oxygenated carbon site on ARA. LOXs have been mainly studied in animals and plants, but rarely in other organisms such as corals, fungi and bacteria. EHs, which catalyse the conversion of epoxides into diols with water molecules, are also important enzymes for lipid mediator synthesis, and widely exist in animals, plants, insects and microorganisms ${ }^{18,19}$. EHs are divided into five types, namely, soluble $\mathrm{EH}$, microsomal $\mathrm{EH}, \mathrm{EH} 3, \mathrm{EH} 4$ and $\mathrm{HX} \mathrm{EH}^{20}$. Although HX EH catalyses the conversion of HXs to TrXs in vivo ${ }^{21}$, it has not been used in the biotransformation of PUFAs to lipid mediators.

To date, the lipid mediators LTs, LXs, RVs, PTs, PGs, HXs and TrXs have not been synthesised by recombinant cells expressing microbial enzymes owing to several reasons. First, most enzymes involved in the synthesis of the lipid mediators have originated from mammals. However, mammalian enzymes have significantly lower activities and stabilities towards ARA than those of microbial enzymes. For example, the specific activity of human 12-LOX for ARA $\left(6.78 \mu \mathrm{mol} \mathrm{min} \mathrm{mg}^{-1} \mathrm{mg}^{-1}\right.$ was significantly lower (approximately 90-fold) than that of the bacterial 12-LOX from Myxococcus xanthus $\left(605 \mu \mathrm{mol} \mathrm{min} \mathrm{mg}^{-1}\right)$. Second, mammalian enzymes need a eukaryotic host with posttranslational modification. However, this host has disadvantages, such as using of expensive medium, low enzyme expression level and difficulty in scaling-up of production. Third, microbial enzymes involved in the synthesis of the lipid mediators have not been identified yet.

Here, we discover bacterium M. xanthus that can produce HXs, TrXs and PGs, and find the biosynthetic genes of HXs, TrXs and PGs from the M. xanthus genome. We synthesize diverse HXs and TrXs from PUFAs by expressing genes of $M$. xanthus involved in the biosynthesis of the lipid mediators in Escherichia coli. Moreover, the transcriptional activity of PPAR $\gamma$ for HXs and TrXs is determined.

\section{Results}

LC-MS analysis for ARA-derived metabolites of M. xanthus. M. xanthus was cultivated in medium containing ARA for $24 \mathrm{~h}$. After cultivation, the culture supernatant was analysed by high performance liquid chromatography (HPLC) and liquid chromatography-mass spectrometry (LC-MS). M. xanthus consumed most of ARA and the peaks of some metabolites were detected (Supplementary Fig. 2). However, ARA was not consumed and there were no new peaks detected in the culture medium without $M$. xanthus. The molecular formulae of metabolites of M. xanthus were determined by MS/MS fragmentation analysis (Supplementary Table 3). Seven types of metabolites were suggested by comparison with the references in the LIPID metabolites and pathways strategy (MAPS) Database. They were eicosapentaenoic acid (EPA; C20:5), 11-hydroxy-5Z,8Z,12E,14Zeicosatetraenoic acid (11-HETE), 12-HETE, 15-HETE, $\mathrm{HXB}_{3}$, $\mathrm{PGG}_{2}$ and $\mathrm{PGH}_{2}$. However, four types of metabolites did not have matched compounds. Among them, metabolite numbers 9 and 10 were possibly new-type of $\mathrm{HX}$ and $\mathrm{TrX}$, respectively, since they did not match with the compounds in available information databases, including the LIPID MAPS Database, PubChem, the Human Metabolome Database and KEGG. The other two types of metabolites were not suggested because they had many overlapping MS/MS fragments.

Identification of the biosynthetic genes and enzymes. Given that the $M$. xanthus genome has already been sequenced, the eight candidate biosynthetic genes of lipid mediators were selected by comparison with the sequences of human corresponding genes. The genes of $M X A N \_1744, \quad M X A N \_1745, \quad M X A N \_1644$, MXAN_5137, MXAN_5217, MXAN_0683, MXAN_2304 and MXAN_3623 in $M$. xanthus were predicted to be the genes encoding LOX, LOX, EH, EH, COX, two thromboxane A (TXA) synthases and PGD synthase, respectively (Supplementary Table 4). Although the amino acid sequences of these enzymes showed 15-40\% identities with human corresponding enzymes $^{23-29}$, the major residues affecting the activity were conserved (Supplementary Fig. 3). These candidate genes were cloned and expressed in E. coli in soluble forms (Supplementary Fig. 4). No activity was found for putative TXA synthases, putative PGD synthase or putative EH expressed from MXAN_5137. The protein from MXAN_5217 converted ARA to $\mathrm{PGH}_{2}$ (Supplementary Fig. 5), indicating that it is COX. The activity of COX towards ARA was $0.011 \mu \mathrm{mol} \mathrm{min}{ }^{-1} \mathrm{mg}^{-1}$. In animals, COX converts ARA to $\mathrm{PGH}_{2}$, which can be converted to diverse PGs by various types of PG synthases (Supplementary Fig. 1). The putative LOX enzymes expressed from $M X A N_{-} 1745$ and MXAN_1744, and the putative EH from MXAN_1644 were purified from crude cell extracts as single soluble proteins using His-Trap affinity chromatography (Supplementary Fig. 4). The substrate specificity and products of these purified enzymes are summarized in Supplementary Table 5. The enzymes from MXAN_1745 and MXAN_1744 converted ARA to 12- 
a

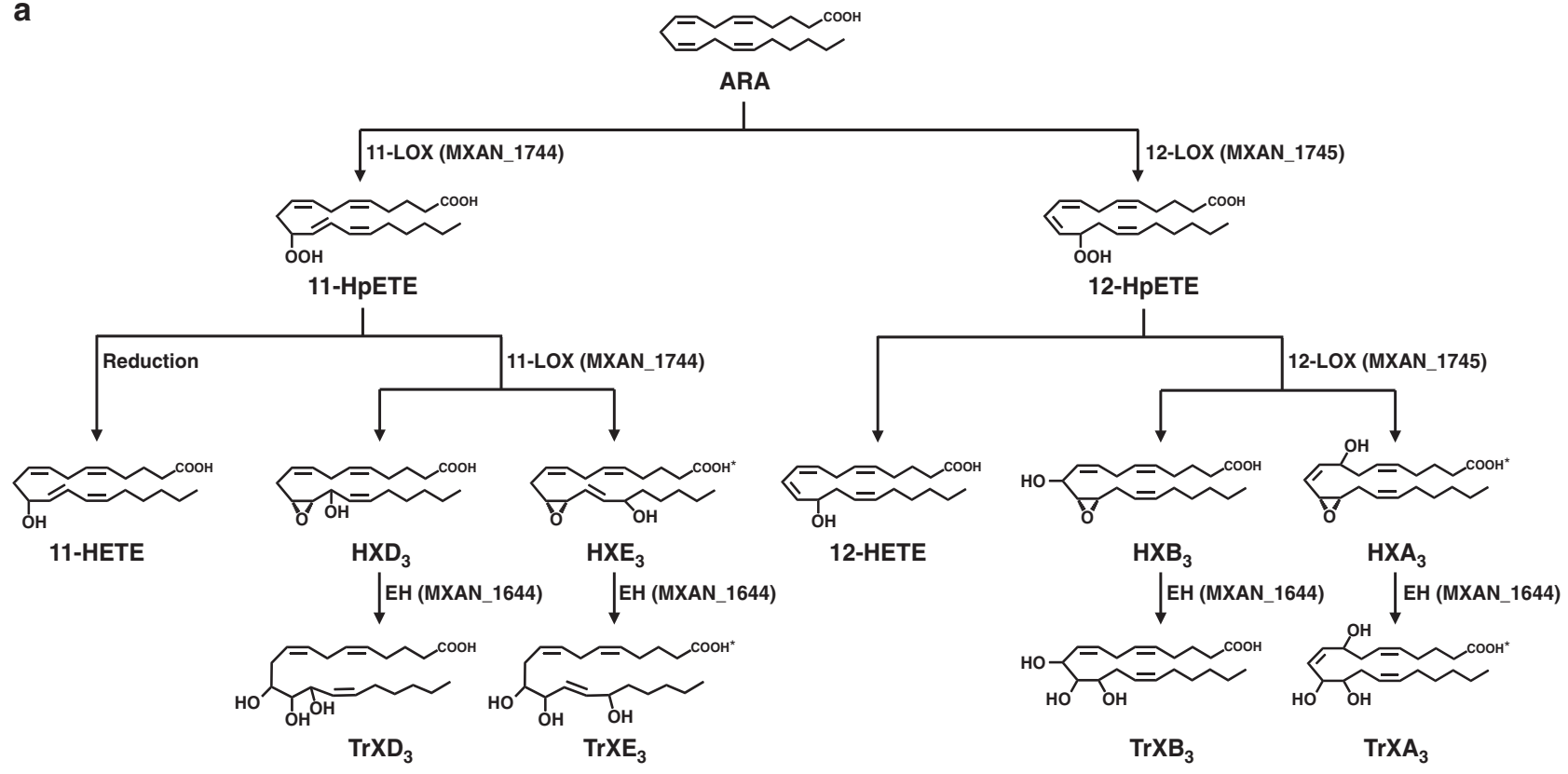

* : These markings indicate the by-products in this pathway.

b

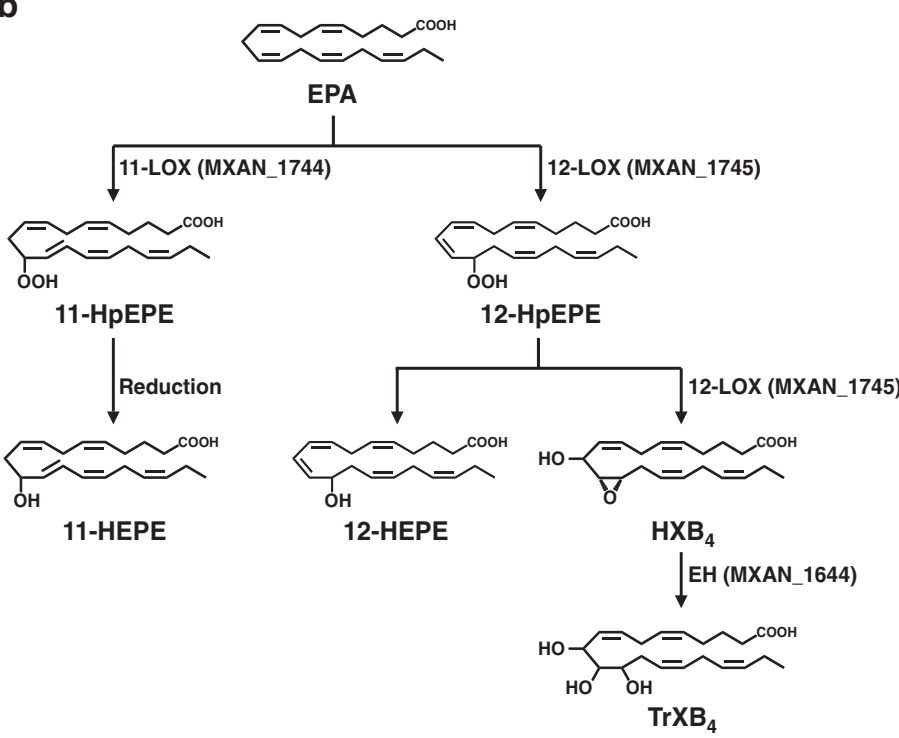

C

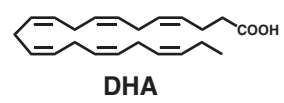

12-LOX (MXAN_1745)

or

11-LOX (MXAN_1744)

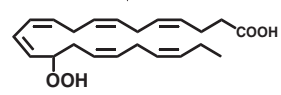

14-HpDoHE

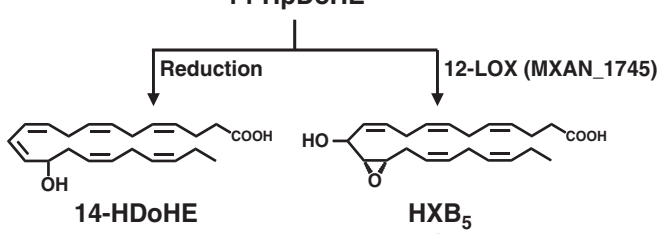

14-HDoHE

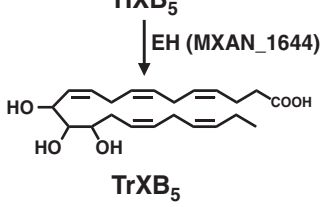

Fig. 1 Pathways of polyunsaturated fatty acids converting to trioxilins established according to the genes of Myxococcus xanthus. PUFA polyunsaturated fatty acid, TrXs trioxilins. a Arachidonic acid (ARA) metabolism. b Eicosapentaenoic acid (EPA) metabolism. c Docosahexaenoic acid (DHA) metabolism

hydroperoxyeicosatetraenoic acid (12-HpETE) and 11-HpETE, respectively, indicating that they are ARA 12-LOX and ARA 11LOX, respectively. The enzyme expressed from MXAN_1644 converted $\mathrm{HXB}_{3}$ to $\mathrm{TrXB}_{3}$. Thus, it was identified as $\mathrm{EH}$. The activities of ARA 12-LOX and ARA 11-LOX towards ARA, and EH towards $\mathrm{HXB}_{3}$ were 605, 489 and $1403 \mu \mathrm{mol} \mathrm{min}{ }^{-1} \mathrm{mg}^{-1}$, respectively, which were 55,000, 44,500 and 127,500-fold higher, respectively, than COX activity. COX from M. xanthus was not used for the biosynthesis of lipid mediators because of its low activity.

Establishment of biosynthetic pathways of PUFAs to TrXs. Although 12-LOX pathways for the conversion of PUFAs to TrXs in humans have already been reported, 11-LOX pathways are not yet known. Recombinant E. coli expressing 12-LOX or 11-LOX and $\mathrm{EH}$ from $M$. xanthus synthesized HXs and TrXs during cultivation with ARA for $120 \mathrm{~min}$ (Supplementary Fig. 6) However, non-enzymatic products were not found with only ARA and E. coli containing ARA in the absence of the plasmid under the same reaction conditions (Supplementary Fig. 7). E. coli expressing 12-LOX and EH produced 12-HpETE, 12-HETE, $\mathrm{HXB}_{3}$ and $\mathrm{TrXB}_{3}$, while E. coli expressing 11-LOX and EH produced 11-HpETE, 11-HETE, $\mathrm{HXD}_{3}$ and $\mathrm{TrXD}_{3}$. These results suggest that HXs and TrXs can be produced by not only 12-LOX pathways but also new 11-LOX pathways.

To investigate more exactly the biosynthetic pathways for the conversion of ARA to TrXs, the reactions were performed using purified enzymes, including 12-LOX, 11-LOX and EH. We found that 12-LOX and 11-LOX converted ARA to 12-HpETE and 11HpETE, respectively, and further to $\mathrm{HXB}_{3}$ and $\mathrm{HxD}_{3}$, respectively, which were then converted to $\mathrm{TrXB}_{3}$ and $\operatorname{TrXD}_{3}$, respectively, by EH. 12-HpETE and 11-HpETE were also 

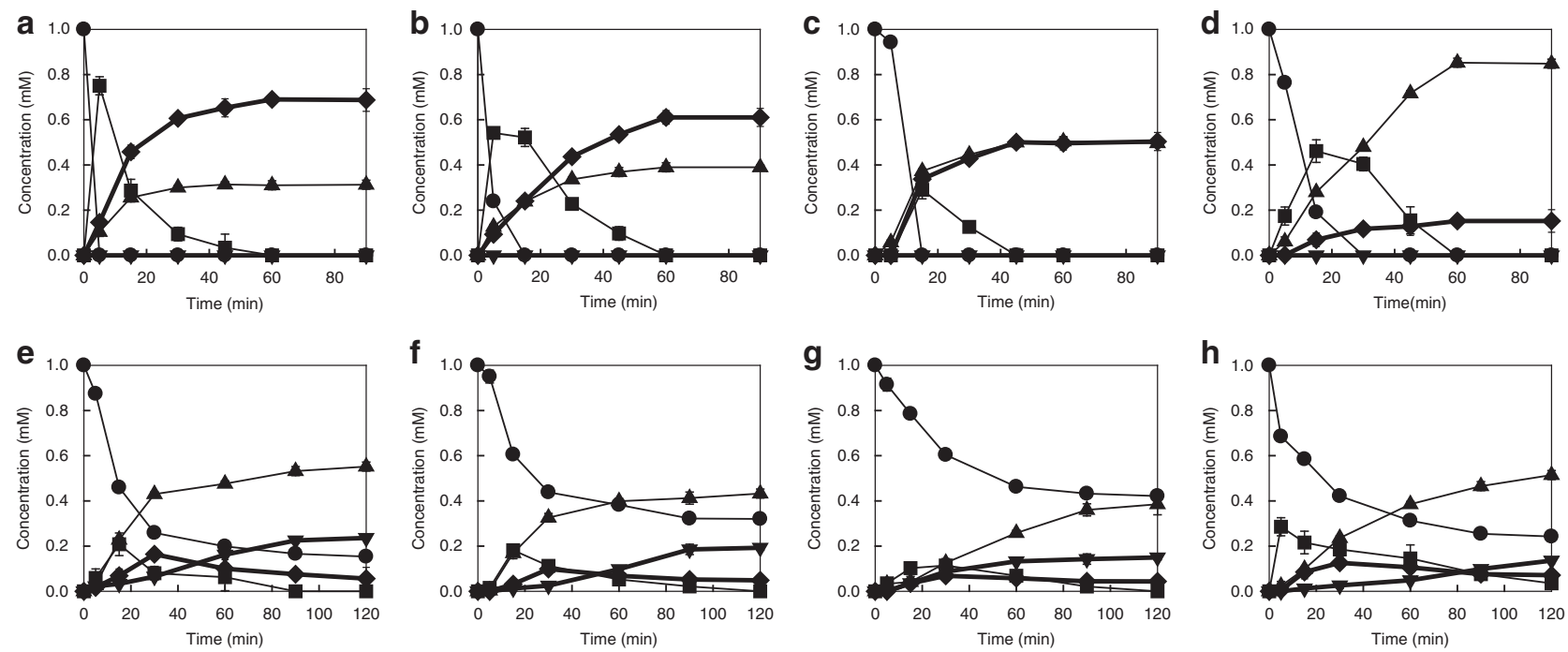

Fig. 2 Biotransformation of polyunsaturated fatty acids to hepoxilins and trioxilins in Escherichia coli. Different combinations of $M$. xanthus genes 12lipoxygenase (12-LOX) or 11-LOX and epoxide hydrolase (EH) were expressed in E. coli strains. HXs hepoxilins, TrXs trioxilins. a Biotransformation of ARA to $\mathrm{HXB}_{3}$ by recombinant $E$. coli expressing 12-LOX. b Biotransformation of EPA to $\mathrm{HXB}_{4}$ by recombinant E. coli expressing 12-LOX. $\mathbf{c}$ Biotransformation of $\mathrm{DHA}$ to $\mathrm{HXB}_{5}$ by recombinant $E$. coli expressing 12-LOX. d Biotransformation of ARA to $\mathrm{HXD}_{3}$ by recombinant $E$. coli expressing 11-LOX. e Biotransformation of ARA to $\operatorname{TrX} B_{3}$ by recombinant E. coli expressing 12-LOX and EH. $\mathbf{f}$ Biotransformation of EPA to $\operatorname{TrX} \mathrm{B}_{4}$ by recombinant $E$. coli expressing 12-LOX and EH. $\mathbf{g}$ Biotransformation of DHA to $\mathrm{TrXB}_{5}$ by recombinant E. coli expressing 12-LOX and EH. $\mathbf{h}$ Biotransformation of ARA to TrXD 3 by recombinant $E$. coli expressing 11-LOX and EH. The time-course reactions were performed in $50 \mathrm{~mm}$ 4-(2-hydroxyethyl)piperazinyl-1-propanesulphonic acid (EPPS) ( $\mathrm{pH}$ 8.5) buffer containing $1 \mathrm{~mm}$ PUFA, $7.2 \mathrm{~g} \mathrm{~L}^{-1}$ cells for ARA or $14.4 \mathrm{~g} \mathrm{~L}^{-1}$ cells for EPA or DHA at $30^{\circ} \mathrm{C}$ for $90-120$ min. Data represent the means of three separate experiments, and error bars represent the standard deviations. The symbols indicate PUFA (circles), hydroperoxy fatty acid (HPFA) (squares), hydroxy fatty acid (HFA) (upward-pointing triangles), HX (diamonds) and $\operatorname{TrX}$ (downward-pointing triangles)

converted to 12-HETE and 11-HETE by natural reduction, respectively. In particular, 11-LOX produced two types of HXs, $\mathrm{HXD}_{3}$ and $\mathrm{HXE}_{3}$. Thus, the 11-LOX and 12-LOX pathways for the conversion of ARA to TrXs were identified (Fig. 1a). We also established the pathways of other eicosanoids, EPA (Fig. 1b) and docosahexaenoic acid (DHA; C22:6), to TrXs using the purified enzymes (Fig. 1c). 12-LOX and 11-LOX converted EPA to 12hydroperoxypentaenoic acid (HpEPE) and 11-HpEPE, respectively. 11-LOX did not convert 11-HpEPE, whereas 12-LOX converted $12-\mathrm{HpEPE}$ to $\mathrm{HXB}_{4}$, which was converted to $\mathrm{TrXB}_{4}$ by EH. 11-LOX and 12-LOX catalysed the same reaction of DHA to 14-hydroperoxydocosahexaenoic acid (HpDoHE). However, only 12-LOX showed epoxidation activity for $14-\mathrm{HpDoHE}$ to $\mathrm{HXB}_{5}$, because 11-LOX activity was significantly lower than 12-LOX activity. $\mathrm{HXB}_{5}$ was converted to $\mathrm{TrXB}_{5}$ by $\mathrm{EH}$.

Identification of all compounds in the pathways. Compounds of HXA series $\left(\mathrm{HXA}_{3}{ }^{30}, \mathrm{HXA}_{4}{ }^{31}\right.$ and $\mathrm{HXA}_{5}{ }^{32}$ ) and TrXA series $\left(\mathrm{TrXA}_{3}, \mathrm{TrXA}_{4}\right.$ and $\operatorname{TrXA}_{5}{ }^{33}$ ) have already been identified. Although HXB and TrXB series have been reported, their chemical structures have not been identified by nuclear magnetic resonance (NMR). The chemical structures of all compounds involved in the established biosynthetic pathways were suggested by LC-MS/MS analysis (Supplementary Figs. 8-10). The suggested compounds $\mathrm{HXB}_{3}, \mathrm{HXB}_{4}, \mathrm{HXB}_{5}, \mathrm{HXD}_{3}, \mathrm{TrXB}_{3}, \operatorname{TrXB}_{4}$, $\mathrm{TrXB}_{5}, \mathrm{TrXD}_{3}$ and $\mathrm{TrXE}_{3}$ were purified by prep-HPLC (Supplementary Fig. 11). Only $S$-form of 12-HpETE has been used to convert to HX in nature ${ }^{34}$. The 12-HETE and 11-HETE products of $M$. xanthus LOXs were also $S$-forms (Supplementary Fig. 12). The stereoselectivity of HXs and TrXs was suggested and the chemical structures were accurately determined except for $\mathrm{TrXE}_{3}$ using NMR analysis (Supplementary Tables 6-14 and Supplementary Figs. 13-57). The determination of the structure of $\mathrm{TrXE}_{3}$ was difficult because the amount produced was very small. Therefore, we just suggested $\mathrm{TrXE}_{3}$ structure (Supplementary
Fig. 53). $\mathrm{HXB}_{5}, \mathrm{HXD}_{3}, \mathrm{HXE}_{3}, \operatorname{TrXB}_{5}, \operatorname{TrXD}_{3}$ and $\operatorname{TrXE}_{3}$ were identified as new compounds, and $\mathrm{HXB}_{3}, \mathrm{HXB}_{4}, \mathrm{TrXB}_{3}$ and $\mathrm{TrXB}_{4}$ were first identified by NMR. The detailed explanation for identification of all compounds in the present study was included in Supplementary Notes and Supplementary Methods.

Biotransformation of PUFAs to HXs and TrXs. The timecourse reactions for the production of HXs and TrXs were performed with $1 \mathrm{mM}$ PUFA or HPFA by recombinant E. coli. E. coli expressing 12-LOX converted $1 \mathrm{~mm}$ of ARA, EPA and DHA to $0.68 \mathrm{mM} \mathrm{HXB}_{3}, 0.61 \mathrm{mM} \mathrm{HXB}_{4}$ and $0.50 \mathrm{mM} \mathrm{HXB}_{5}$, respectively, in $90 \mathrm{~min}$, with molar conversions of $68 \%, 61 \%$ and $50 \%$, respectively (Fig. 2); converted $1 \mathrm{mM}$ of 12-HpETE, 12-HpEPE and 14-HpDoHE as intermediates to $0.76 \mathrm{mM} \mathrm{HXB}_{3}, 0.51 \mathrm{mM}$ $\mathrm{HXB}_{4}$ and $0.53 \mathrm{mM} \mathrm{HXB}_{5}$, respectively, in $60 \mathrm{~min}$ (Supplementary Fig. 58); and produced $2.15 \mathrm{mM} \mathrm{HXB}_{3}$ from $6 \mathrm{mM}$ ARA after 60 min, with a conversion of $36 \%$ (Supplementary Fig. 59). E. coli expressing 11-LOX converted $1 \mathrm{mM}$ ARA to $0.15 \mathrm{mM} \mathrm{HXD}_{3}$ in $90 \mathrm{~min}$ and converted $1 \mathrm{mM} 11-\mathrm{HpETE}$ to $0.27 \mathrm{mM} \mathrm{HXD}_{3}$ in 60 min (Fig. 2d and Supplementary Fig. 58d). E. coli co-expressing 12-LOX and EH converted $1 \mathrm{mM}$ of ARA, EPA and DHA to 0.23 $\mathrm{mM} \mathrm{TrXB}_{3}, 0.19 \mathrm{mM} \mathrm{TrXB}_{4}$ and $0.14 \mathrm{mM} \mathrm{TrXB}_{5}$, respectively, in $120 \mathrm{~min}$ (Fig. 2e-g), and E. coli co-expressing 11-LOX and $\mathrm{EH}$ converted $1 \mathrm{mM}$ ARA to $0.13 \mathrm{mM} \mathrm{TrXD}_{3}$ in $120 \mathrm{~min}$ (Fig. $2 \mathrm{~h}$ ).

Determination on the transcriptional activity of PPAR $\gamma$. PPAR $\gamma$, a type II nuclear receptor, regulates fatty acid storage and glucose metabolism. Its agonists have been used in the treatment of hyperlipidaemia and hyperglycaemia. The effects of HETEs, HXs and TrXs on the transcriptional activity of PPAR $\gamma$ were investigated to find PPAR $\gamma$ agonists. The effects of $\mathrm{HXB}_{3}, \mathrm{HXB}_{5}$ and $\mathrm{HXD}_{3}$ on the transcriptional activity of PPAR $\gamma$ were similar to those of their corresponding TrXs. $\mathrm{HXB}_{3}$ and $\mathrm{HXD}_{3}\left(\mathrm{TrXB}{ }_{3}\right.$ and $\operatorname{TrXD}_{3}$ ) increased the transcriptional activity of PPAR $\gamma$ with increasing concentrations, although the increasing degrees of the 
a

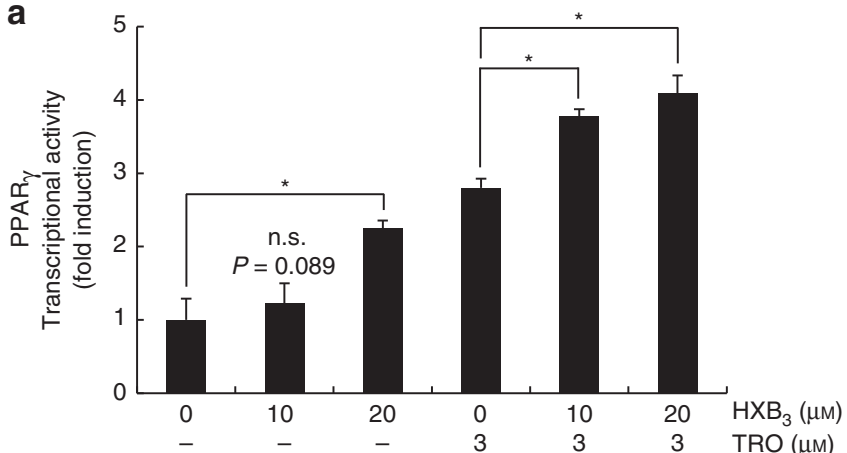

b

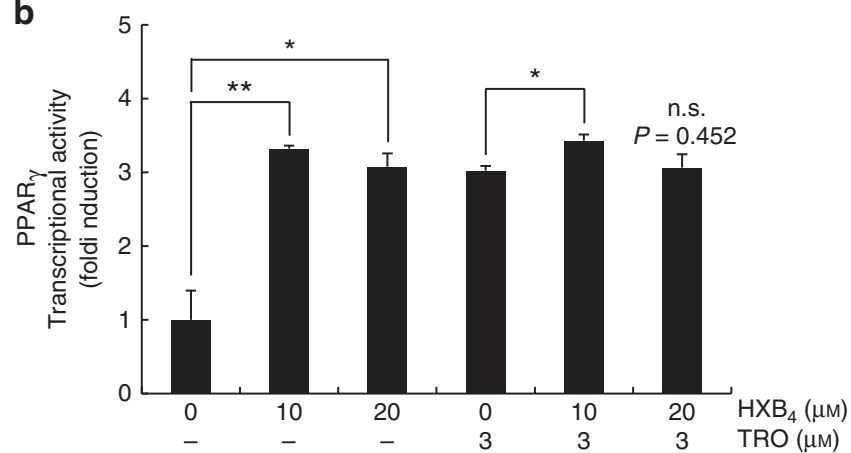

C

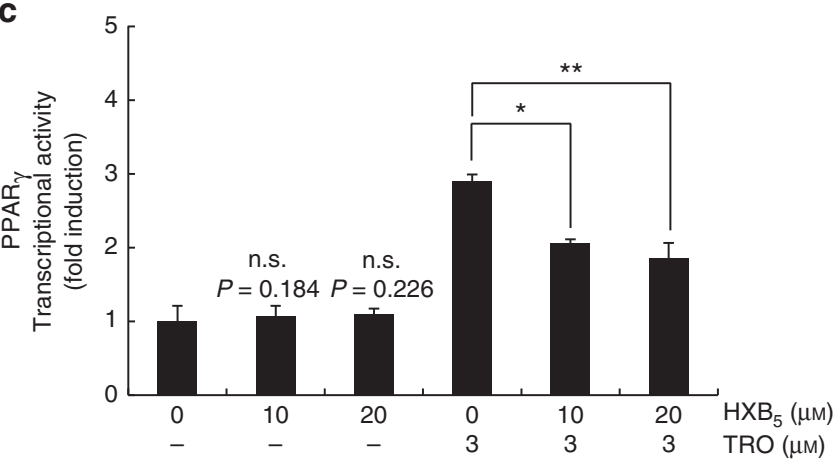

d

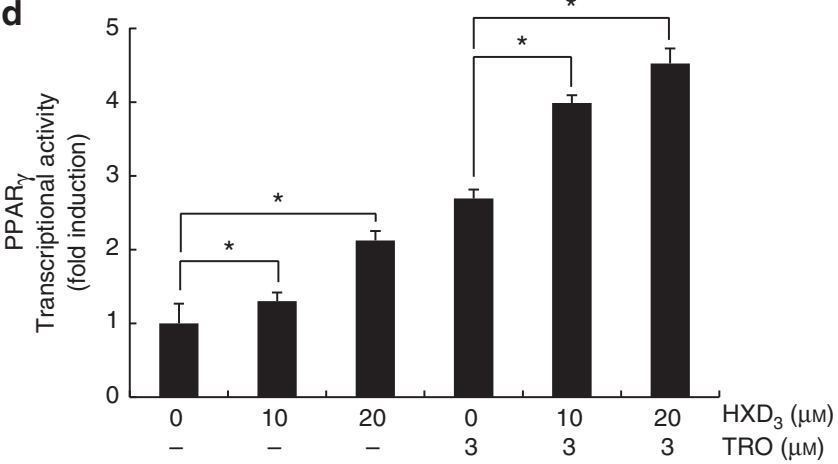

$\mathbf{f}$

e

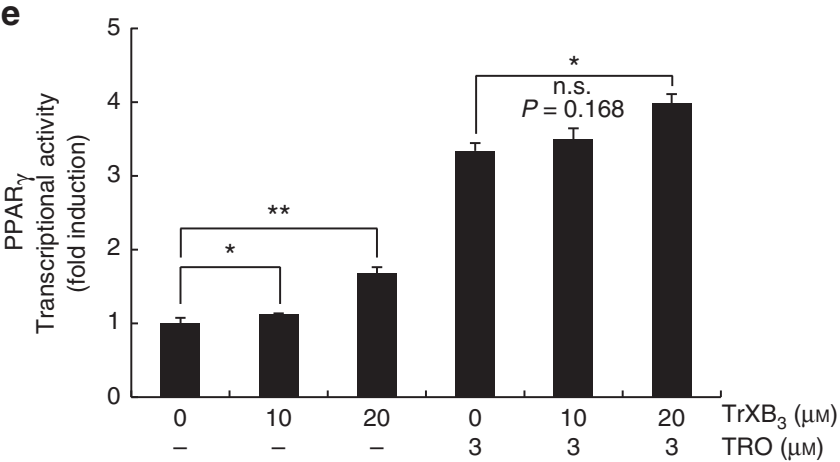

g

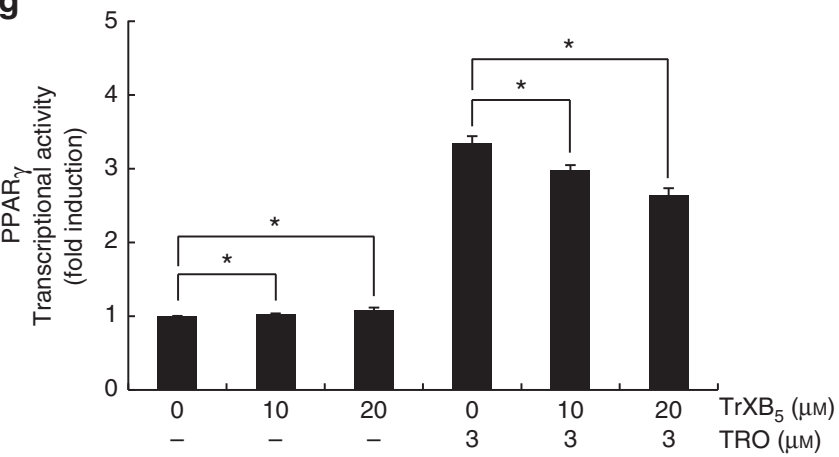

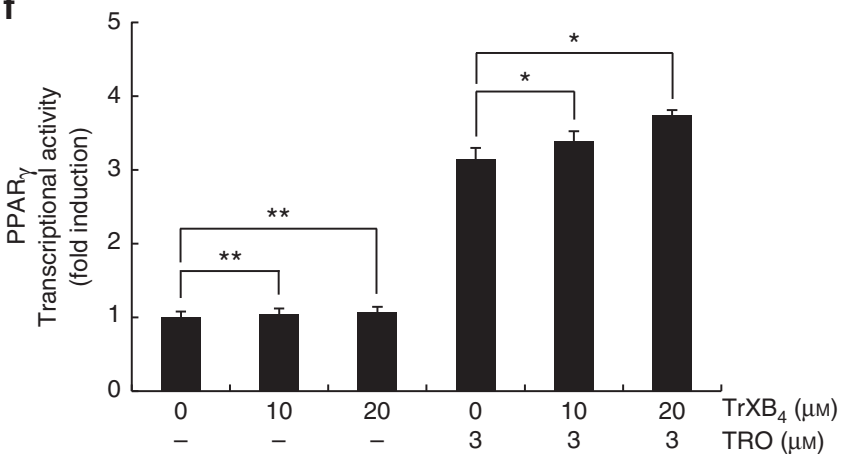

h

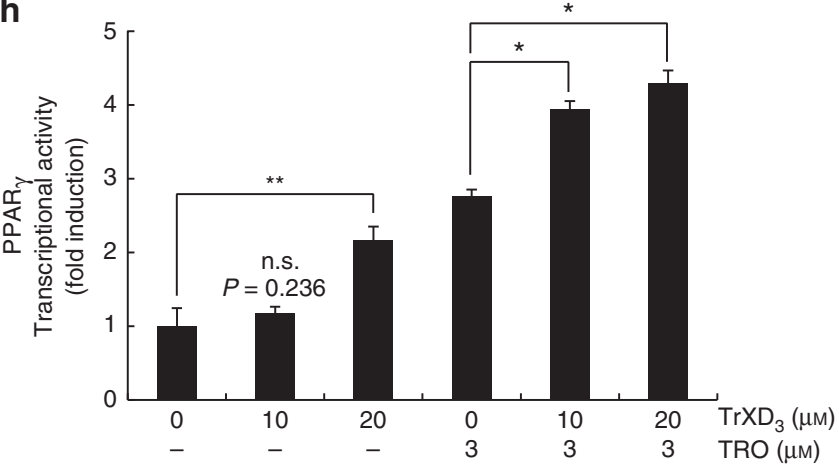

Fig. 3 Transcriptional activity of peroxisome proliferator-activated receptor gamma for hepoxilins and trioxilins. HEK-293 cells were cultured in a 24 -well plate $\left(1.0 \times 10^{5}\right.$ cells per well). After $24 \mathrm{~h}$, cells were transfected with plasmids expressing peroxisome proliferator-activated receptor gamma (PPAR $\gamma$ ), PPAR response element (PPRE) $\times 3$-thymidine kinase-luciferase reporter constructs, and the Renilla luciferase control vector pRL. After another $24 \mathrm{~h}$, cells were treated with $\mathrm{HXs}$, TrXs and/or $3 \mu \mathrm{m}$ troglitazone (TRO) for $24 \mathrm{~h}$. Cells were harvested, and the transcriptional activity of PPAR $\gamma$ was determined by a

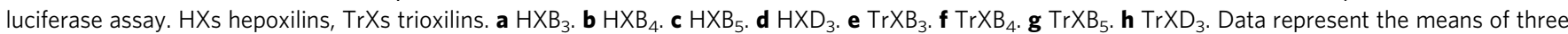
separate experiments, and error bars represent the standard deviations. $p$-value are based on $t$-test. ${ }^{\star} p<0.05,{ }^{\star \star} p<0.01$. n.s. indicates not significant 
transcriptional activity were less than that of troglitazone (TRO), an antidiabetic and anti-inflammatory drug (Fig. 3). These compounds additively increased the transcriptional activity of PPAR $\gamma$ when TRO was supplemented. The increasing degree of the transcriptional activity for $\mathrm{HXB}_{4}$ was similar to that by TRO (Fig. 3b). $\mathrm{HXB}_{5}, \operatorname{TrXB}_{4}$ and $\operatorname{TrXB}_{5}$ did not affect the activity (Fig. 3c, f, g). However, $\mathrm{HXB}_{5}$ decreased the transcriptional activity of PPAR $\gamma$ when TRO was supplemented. 11-HETE and 12-HETE as intermediate products showed effects similar to those of $\mathrm{HXB}_{3}$ and $\mathrm{HXB}_{5}$, respectively, on the transcriptional activity of PPAR $\gamma$ (Supplementary Fig. 60).

\section{Discussion}

Lipid mediators regulate the immune and inflammatory responses of humans. LOXs are key enzymes involved in the formation of lipid mediators in animals and humans ${ }^{35}$. Recently, LOXs have been discovered in diverse organisms such as $\operatorname{coral}^{36}$, fungi ${ }^{9}, 37$ and bacteria ${ }^{38}$. Among them, bacterial LOXs have only been found in the cyanobacteria Nostoc sp. ${ }^{39}$ and Acaryochloris marina $^{40}$, and the proteobacteria Pseudomonas aeruginosa ${ }^{41}$ and Burkholderia thailandensis ${ }^{38}$ (Supplementary Fig. 61 and Supplementary Table 15). M. xanthus is also a proteobacterium. Interestingly, LOXs in other proteobacteria have regiospecificity on C15 of ARA, whereas LOXs in M. xanthus has regiospecificity on $\mathrm{C} 12$ and $\mathrm{C} 11$ of ARA. Bacteria containing LOXs may produce lipid mediators. However, the formation of HXs and TrXs by bacterial LOXs has not been reported thus far.

In humans, HX is formed from ARA via 12-HpETE by dioxygenation and epoxidation reactions of $12-\mathrm{LOX}^{42}$. $\mathrm{HXA}_{3}{ }^{9}$ and $\mathrm{HXB}_{3}{ }^{30}, \mathrm{HXA}_{4}$ and $\mathrm{HXB}_{4}{ }^{31}$, and $\mathrm{HXA}_{5}{ }^{32}$ are formed from ARA, EPA and DHA, respectively. Then, these HXs are converted to $\mathrm{TrXA}_{3}, \operatorname{TrXB}_{3}, \operatorname{TrXA}_{4}, \operatorname{TrXB}_{4}$ and $\operatorname{TrXA}_{5}$, in vivo by $\mathrm{EH}$, respectively (Supplementary Fig. 62). 15-LOX also converts ARA to $\mathrm{HX}$ analogues ${ }^{43}$. $\mathrm{TrXC}_{3}$ is specifically produced from $\mathrm{HXA}_{3}{ }^{33}$. In this study, 12-LOX from $M$. xanthus converted ARA, EPA and $\mathrm{DHA}$ to $\mathrm{HXB}_{3}, \mathrm{HXB}_{4}$ and $\mathrm{HXB}_{5}$, respectively, which were further converted to $\operatorname{TrXB}_{3}, \operatorname{TrXB}_{4}$ and $\operatorname{TrXB}_{5}$, respectively, by EH from M. xanthus (Fig. 1). Among them, $\mathrm{HXB}_{5}$ and $\mathrm{TXB}_{5}$ were the new products. 11-LOX, catalysing dioxidation on C11 in ARA, has not been reported in animals but exists in the cyanobacterium $A$. marina and some algae ${ }^{40,44}$. 11-LOX discovered in the proteobacterium $M$. xanthus converted ARA to new HXs with hydroxyl groups located at $\mathrm{C} 13$ and $\mathrm{C} 15$ (Fig. 1a). We named these HXs as $\mathrm{HXD}_{3}$ and $\mathrm{HXE}_{3}$, respectively, which were converted to the new compounds $\mathrm{TrXD}_{3}$ and $\mathrm{TrXE}_{3}$, respectively, by EH. The experiments for the presence or absence of these compounds in mammalian tissues using ${ }^{14} \mathrm{C}$-labeled ARA were performed by other research groups ${ }^{5,32}$. As a result, $\mathrm{HXD}_{3}$ and $\mathrm{TrXD}_{3}$ were not found in human and rat tissues. Thus, not only 11-LOX but also 11-LOX-derived products such as $\mathrm{HXD}_{3}$ and $\operatorname{TrXD}_{3}$ do not exist in mammalian tissues.

We found the lipid mediators HXs, TrXs and PGs in the culture broth containing ARA and M. xanthus (Supplementary Table 3), and identified 12-LOX, 11-LOX, EH and COX as the related enzymes in $M$. xanthus (Supplementary Table 4). HXs and TrXs were produced from PUFAs by E. coli expressing these bacterial enzymes. The production is our unprecedented discovery. The availability of HXs and TrXs has been strictly limited because there is only one reagent-grade $\mathrm{HXA}_{3}$ commercially available. However, recombinant cells in the present study converted $1 \mathrm{mM}$ PUFAs to four types of HXs with more than 50\% conversion (Fig. 2a-d) and four types of TrXs with more than $10 \%$ conversion (Fig. 2e-h). These conversion rates may be sufficient for the economical production of diverse HXs and TrXs, which opens the door for physiological studies and drug development.
PPAR $\gamma$ is an important nuclear receptor functioning in lipid accumulation ${ }^{45}$, glucose metabolism ${ }^{46}$, inflammatory response ${ }^{47}$, neutrophil transmigration ${ }^{48}$, vascular permeability ${ }^{49}$ and hyperalgesia ${ }^{50}$. Thiazolidinediones (TMZs) such as rosiglitazone ${ }^{51}$ and $\mathrm{TRO}^{52}$ are representative full agonists of PPAR $\gamma$. Full agonists have side effects such as weight gain and worsening of congestive heart failure ${ }^{53}$, whereas partial agonists retain beneficial antidiabetic properties with reduced side effects ${ }^{34}$. Partial agonists are defined as weak activators of PPAR $\gamma$ that show the same activation pattern with lower transactivation potential compared to full agonists ${ }^{54}$. The ligand binding domain (LBD) of PPAR $\gamma$ consists of a bundle of $13 \alpha$-helices and $4 \beta$-strands, and agonists are bind to helices $\mathrm{H} 3, \mathrm{H} 5, \mathrm{H} 10$ and $\mathrm{H} 12$, including the major residues Ser289 (H3), His323 (H5), His449 (H10) and Tyr473 (H12) ${ }^{55}$. Full agonists of PPAR such as TMZs are known to bind to H12, whereas partial agonists stabilize the $\mathrm{H} 2^{\prime} / \mathrm{H} 3$ and $\mathrm{H} 5$ areas, resulting in distinct transcriptional effects between full and partial agonists ${ }^{25}$. Thus, the additive effects of full and partial PPAR $\gamma$ agonists exist ${ }^{56}$. In this study, the transcriptional activity of PPAR $\gamma$ in response to the ten types of lipid mediators produced by $M$. xanthus enzymes was investigated (Fig. 3 and Supplementary Fig. 60) because fatty acids have played a role as modulators of PPAR $\gamma^{57}$. $\mathrm{HXB}_{3}, \mathrm{HXB}_{4}, \mathrm{HXD}_{3}, \mathrm{TrXB}_{3}, \mathrm{TrXD}_{3}$ and 11-HETE increased the transcriptional activity of PPAR $\gamma$. These compounds were docked to LBD at human PPAR $\gamma$ using molecular models (Supplementary Fig. 63). Rosiglitazone, known as a full agonist, was interacted with Tyr473 (H12) (Supplementary Fig. 64a). $\mathrm{HXB}_{3}$, $\mathrm{HXB}_{4}, \mathrm{HXD}_{3}, \mathrm{TrXB}_{3}, \mathrm{TrXD}_{3}$ and 11-HETE were interacted with Ser289 (H3) and His323 (H5) (Supplementary Fig. 64b-g), suggesting that these compounds are partial agonists. However, this study does not demonstrate direct agonist activities of these products.

In conclusion, we discovered eukaryotic-like lipid mediatorbiosynthetic enzymes, including 12-LOX, 11-LOX, COX and EH, from M. xanthus, a newly discovered bacterium that could produce HXs, TrXs and PGs. Owing to the high activities of microbial enzymes, we succeeded in the biotransformation of PUFAs to eight types of HXs and TrXs using recombinant cells expressing 12-LOX or 11-LOX with or without EH. The same strategy can be applied to the biotransformation processes of PUFAs to other lipid mediators such as LTs, LXs, RVs and PTs. We identified ten types of lipid mediators including six new types based on NMR analysis. We found that six types of lipid mediators were potential partial agonists of PPAR $\gamma$. The identification of partial agonists of PPAR $\gamma$ has been required for development of the antidiabetic and anti-inflammatory drugs with reduced side effects. Thus, outcomes of this study may hold potential to stimulate physiological studies and drug development on lipid mediators.

\section{Methods}

Materials. The PUFA standards ARA, EPA and DHA, and the HFA standards 11-HETE, 12-HETE, 12-HEPE and 14-HDoHE were purchased from Sigma (St. Louis, MO, USA) and Cayman Chemical (Ann Arbor, MI, USA), respectively. To prepare the lipid mediator standards $\mathrm{HXB}_{3}, \mathrm{HXB}_{4}, \mathrm{HXB}_{5}, \mathrm{HXD}_{3}, \operatorname{TrXB}_{3}$, $\operatorname{TrXB}_{4}, \operatorname{TrXB}_{5}$ and $\operatorname{TrXD}_{3}$, the reactions were performed at $30^{\circ} \mathrm{C}$ in $50 \mathrm{mM}$ 4-(2-hydroxyethyl)piperazinyl-1-propanesulphonic acid (EPPS) buffer ( $\mathrm{pH} \mathrm{8.5)}$ containing $100 \mathrm{mg} \mathrm{L}^{-1}$ of ARA, EPA or DHA as a substrate, and $14.4 \mathrm{~g} \mathrm{~L}^{-1}$ recombinant cells with shaking at 200 r.p.m. for $2 \mathrm{~h}$. The reaction solution was extracted with an equal volume of ethyl acetate, and the solvent was removed using a rotary evaporator. The solvent-free solution was applied to a Prep-HPLC (Agilent 1260, Santa Clara, CA, USA) equipped with a Nucleosil C18 column $(10 \times 250 \mathrm{~mm}$, 5 - $\mu \mathrm{m}$ particle size; Phenomenex, Torrance, CA, USA) and a fraction collector. The column was eluted at $30{ }^{\circ} \mathrm{C}$ with a flow rate of $6 \mathrm{~mL} \mathrm{~min}^{-1}$, and the product fractions were collected by monitoring at $202 \mathrm{~nm}$ of absorbance. The collected samples showed $>99 \%$ purity (Supplementary Fig. 11), and were used as the lipid mediator standards after identification by LC-MS/MS and NMR. 
Plasmids and microorganisms culture conditions. M. xanthus KCCM 44251 (Korea Culture Center of Microorganisms, Seoul, Republic of Korea), E. coli BL21, and pET-28a and pACYC duet plasmids were used as the source of genomic DNA, host cells and expression vectors, respectively. M. xanthus was cultivated in a 500$\mathrm{mL}$ flask containing $100 \mathrm{~mL}$ of Casitone medium supplemented with $1 \mathrm{mM}$ ARA at $30{ }^{\circ} \mathrm{C}$ with shaking at 200 r.p.m. for 24 h. Recombinant E. coli was cultivated in a 2L flask containing $450 \mathrm{~mL}$ of Luria-Bertani (LB) medium supplemented with $20 \mu \mathrm{g}$ $\mathrm{mL}^{-1}$ kanamycin for pET-28a or chloramphenicol for pACYC duet vector at $37^{\circ} \mathrm{C}$ with shaking at 200 r.p.m. When the optical density of the bacterial culture at 600 $\mathrm{nm}$ reached $0.6,0.1 \mathrm{mM}$ isopropyl- $\beta$-D-thioglactopyranoside was added, and the incubation continued with shaking at 150 r.p.m. at $16^{\circ} \mathrm{C}$ for $18 \mathrm{~h}$ to induce enzyme expression.

Gene cloning. The genes encoding candidate enzymes were amplified by PCR using M. xanthus genomic DNA as a template (Supplementary Table 4). The primers used for gene cloning were designed based on the DNA sequence of candidate enzymes from M. xanthus (Supplementary Table 16). DNA fragments obtained by PCR amplification with Taq polymerase (Solgent, Daejon, Korea) were ligated into the pET-28a or pACYC duet vector. The resulting plasmid was transformed into E. coli BL21 and then plated on LB agar containing $20 \mu \mathrm{g} \mathrm{mL}^{-1}$ kanamycin (pET 28a vector) or chloramphenicol (pACYC duet vector). An antibiotic-resistant colony was selected, and the plasmid DNA was sequenced using a DNA analyser (ABI Prism 3730xl; Perkin-Elmer, Waltham, MA, USA).

Enzyme purification. Harvested cells were suspended in $50 \mathrm{mM}$ phosphate buffer (pH 8.0) containing $10 \mathrm{mM}$ imidazole, $300 \mathrm{mM} \mathrm{NaCl}$ and $0.1 \mathrm{mM}$ phenylmethylsulphonyl fluoride as a protease inhibitor, and disrupted by sonication on ice bath. Cell debris was removed by centrifugation at $13,000 \times \mathrm{g}$ for $10 \mathrm{~min}$ at $4{ }^{\circ} \mathrm{C}$, and the supernatant was applied to an immobilized metal ion affinity chromatography cartridge (Bio-Rad, Hercules, CA, USA) equilibrated with $50 \mathrm{mM}$ phosphate buffer ( $\mathrm{pH} 8.0$ ) containing $300 \mathrm{mM} \mathrm{NaCl}$. The bound protein was eluted by the same buffer with a linear gradient of $10-250 \mathrm{mM}$ imidazole at a flow rate of 1 $\mathrm{mL} \mathrm{min}^{-1}$. The active fractions were collected and loaded onto a Bio-Gel P-6 desalting cartridge (Bio-Rad) equilibrated with $50 \mathrm{mM}$ EPPS buffer ( $\mathrm{pH}$ 8.5). The loaded protein was eluted using the same buffer at a flow rate of $1 \mathrm{~mL} \mathrm{~min}{ }^{-1}$, and the eluted protein was used as the purified enzyme.

Enzyme and cell reactions. To measure the specific activities of the enzymes, the reactions were performed at $30^{\circ} \mathrm{C}$ in $50 \mathrm{mM}$ EPPS ( $\mathrm{pH} \mathrm{8.5)} \mathrm{containing} 1 \mathrm{mM}$ substrate and $0.12-2.0 \mathrm{~g} \mathrm{~L}^{-1}$ of 12-LOX, 11-LOX, EH or COX for $5 \mathrm{~min}$. The reactions for the conversion of PUFAs into lipid mediators were performed at $30^{\circ}$ $\mathrm{C}$ in $50 \mathrm{mM}$ EPPS ( $\mathrm{pH}$ 8.5) containing $1-6 \mathrm{mM}$ substrate and $3.6-14.4 \mathrm{~g} \mathrm{~L}^{-1}$ cells for $120 \mathrm{~min}$. The optical density at $600 \mathrm{~nm}$ of the cell suspension was measured and converted to dry cell weight.

Transcriptional activity assay. Human embryonic kidney (HEK) 293 cells have been widely used for the screening of PPAR $\gamma$ agonists $^{58}$, suggesting that the endogenous factor of HEK293 cells do not affect the transcriptional activity of PPAR $\gamma$. The lipid mediators tested were not metabolized by HEK 293 cells (Supplementary Fig. 65). To investigate the effects of lipid mediators on the transcriptional activity of PPAR $\gamma$, HEK 293 cells were cultivated in 24-well plates $\left(1 \times 10^{5}\right.$ cells per well) containing Dulbecco's modified Eagle's medium with $10 \%$ foetal bovine serum for $24 \mathrm{~h}$. Cultured cells were transfected with plasmids expressing PPAR $\gamma$ and PPAR response element $\times 3$-thymidine kinase-luciferase reporter constructs $(1 \mu \mathrm{g}$ per well) using the transfection reagent Lipofectamine 2000 (Invitrogen, Carlsbad, CA, USA). After $24 \mathrm{~h}$, cells were treated with 5-20 $\mu \mathrm{M}$ lipid mediator and/or $3 \mu \mathrm{M}$ TRO. The high micromolar concentration of HETE, HX or TrXs up to $20 \mu \mathrm{M}$ was used to determine the transcriptional activity of $\operatorname{PPAR} \gamma$ because there was no cytotoxicity at this concentration. The concentration up to $20-40 \mu \mathrm{M}$ has been used for PPAR $\gamma$ partial agonists due to their weak activity and no cytotoxicity ${ }^{59-61}$. The concentration of the full agonist TRO was the same as those used in other reports ${ }^{47,62}$. After another $24 \mathrm{~h}$, harvested cells were assayed with a dual-luciferase reporter gene assay kit (Promega, Madison, WI, USA). The activities are presented as the expression ratio of firefly luciferase to Renilla luciferase.

Phylogenetic analysis. 12-LOX and 11-LOX from $M$. xanthus were used as query sequences for a blast search against the genomic sequences of other organisms. All hits with an expected value of $<\mathrm{e}^{-10}$ were compiled from the database and aligned using the MUSCLE algorithm in MEGA 6. Sequences with poor alignment and annotated as unrelated proteins were removed. Phylogenetic trees were built using the neighbour-joining method in MEGA 6 with 1000 bootstraps.

HPLC quantitative analysis. All compounds were quantitatively analysed using an HPLC system (Agilent 1260) with a reversed-phase Nucleosil C18 column $(3.2 \times 150 \mathrm{~mm}, 5-\mu \mathrm{m}$ particle size; Phenomenex). Absorbance at 202 and $234 \mathrm{~nm}$ has been used in HPLC analysis for monitoring non-conjugated HFAs, including HXs, TrXs and PGs, and absorbance at $234 \mathrm{~nm}$ has been used for monitoring conjugated HFAs ${ }^{63}$. HXA 3 has been also monitored at $254 \mathrm{~nm}^{64}$. HXs and TrXs were detected at a wavelength of $202 \mathrm{~nm}$ but not at 234 and $254 \mathrm{~nm}$ (Supplementary Fig. 66). Thus, all products were monitored at $202 \mathrm{~nm}$. The column was eluted at $30^{\circ} \mathrm{C}$ with $100 \%$ solvent A (acetonitrile/water/acetic acid, 50:50:0.1, v/v/v) at a flow rate of $0.25 \mathrm{~mL} \mathrm{~min}^{-1}$ for $0-5 \mathrm{~min}$, solvent $\mathrm{A}$ to solvent $\mathrm{B}$ (acetonitrile/ acetic acid, $100: 0.1, \mathrm{v} / \mathrm{v}$ ) for $5-21 \mathrm{~min}$ at $0.25 \mathrm{~mL} \mathrm{~min}^{-1}, 100 \%$ solvent $\mathrm{B}$ at $0.4 \mathrm{~mL}$ $\mathrm{min}^{-1}$ for $21-27 \mathrm{~min}$, solvent $\mathrm{B}$ to solvent $\mathrm{A}$ at $0.4 \mathrm{~mL} \mathrm{~min}^{-1}$ for $27-32 \mathrm{~min}$, and $100 \%$ solvent $\mathrm{A}$ at $0.25 \mathrm{~mL} \mathrm{~min}^{-1}$ for $32-35 \mathrm{~min}$. The reaction products were identified to have the same retention times as those of their corresponding standards. The concentrations of PUFAs, HPFAs, HFAs, HXs and TrXs were calculated by calibrating the peak areas to the concentrations of standards. For an example, the determination method for the concentration of $\mathrm{HXB}_{3}$ using a calibration curve was provided in Supplementary Fig. 67.

In silico docking studies. Metabolites were docked in the LBD of crystal structure of human PPAR $\gamma$ (PDB 2PGR.pdb) using the CDOCKER module of Discovery Studio 4.1 (Accelrys, San Diego, CA, USA). Substrate poses were refined by fullpotential final minimization, and candidate poses were created using random rigid body rotations followed by simulated annealing. The structure of protein-ligand complexes was subjected to energy minimization using the CHARMM force field in DS 4.5. The substrate orientation with the lowest interaction energy was selected for the subsequent rounds of docking. Candidate poses were created based on random rigid-body rotations followed by simulated annealing. The energy-docked conformation of the substrate was retrieved for post-docking analysis using the CDOCKER module.

Statistical analyses. The means and standard errors for all experiments were quantitatively calculated with $t$-test to evaluate significant differences between control and experimental groups. A $p$-value of $<0.05$, calculated using $t$-test, was considered statistically significant.

Data availability. Plasmids used in this article were deposited in Addgene. They were assigned to pET28a-mxLOX1 (ID 104975), pET28a-mxLOX2 (ID 104976), pET28a-mxEH (ID 104977), pACYCduet-mxLOX1-EH (ID 104978) and pACYCduet-mxLOX2-EH (ID 104979). All data that support the findings of this study are included in this article and in Supplementary Information. They are available from the corresponding author upon request.Ed.: Please confirm the plasmid IDs you deposited in Addgene are publicly available.Now, we are prepared our plasmids for deposition and will send to Addgene within this week. Therefore, the plasmid IDs will be available soon.

Received: 5 June 2017 Accepted: 8 December 2017

Published online: 09 January 2018

\section{References}

1. Buckley, C. D. et al. The resolution of inflammation. Nat. Rev. Immunol. 13, 59-66 (2013)

2. Pace-Asciak, C. R., Wong, L. \& Corey, E. J. Hepoxilin $A_{3}$ blocks the release of norepinephrine from rat hippocampal slices. Biochem. Biophys. Res. Commun. 173, 949-953 (1990).

3. Laneuville, O., Corey, E. J., Couture, R. \& Pace-Asciak, C. R. Hepoxilin $\mathrm{A}_{3}$ $\left(\mathrm{HxA}_{3}\right)$ is formed by the rat aorta and is metabolized into $\mathrm{HxA}_{3}-\mathrm{C}$, a glutathione conjugate. Biochim. Biophys. Acta 1084, 60-68 (1991).

4. Shankaranarayanan, P., Ciccoli, R. \& Nigam, S. Biosynthesis of hepoxilins: evidence for the presence of a hepoxilin synthase activity in rat insulinoma cells. FEBS Lett. 538, 107-112 (2003).

5. Anton, R. \& Vila, L. Stereoselective biosynthesis of hepoxilin $\mathrm{B}_{3}$ in human epidermis. J. Invest. Dermatol. 114, 554-559 (2000).

6. Margalit, A. et al. Hepoxilin $\mathrm{A}_{3}$ is the endogenous lipid mediator opposing hypotonic swelling of intact human platelets. Proc. Natl. Acad. Sci. USA 90, 2589-2592 (1993).

7. Sutherland, M., Schewe, T. \& Nigam, S. Biological actions of the free acid of hepoxilin $\mathrm{A}_{3}$ on human neutrophils. Biochem. Pharmacol. 59, 435-440 (2000).

8. Pace-Asciak, C. R. \& Martin, J. M. Hepoxilin, a new family of insulin secretagogues formed by intact rat pancreatic islets. Prostaglandins Leukot. Med. 16, 173-180 (1984)

9. Derewlany, L. O., Pace-Asciak, C. R. \& Radde, I. C. Hepoxilin $\mathrm{A}_{3}$, hydroxyepoxide metabolite of arachidonic acid, stimulates transport of $45 \mathrm{Ca}$ across the guinea pig visceral yolk sac. Can. J. Physiol. Pharmacol. 62, 1466-1469 (1984).

10. Belardetti, F. et al. Products of heme-catalyzed transformation of the arachidonate derivative $12-\mathrm{HpETE}$ open S-type $\mathrm{K}^{+}$channels in Aplysia. Neuron 3, 497-505 (1989). 
11. Margalit, A. \& Granot, Y. Endogenous hepoxilin $\mathrm{A}_{3}$, produced under short duration of high shear-stress, inhibits thrombin-induced aggregation in human platelets. Biochim. Biophys. Acta 1190, 173-176 (1994).

12. Jankov, R. P. et al. Hepoxilin analogs inhibit bleomycin-induced pulmonary fibrosis in the mouse. J. Pharmacol. Exp. Ther. 301, 435-440 (2002).

13. Mrsny, R. J. et al. Identification of hepoxilin $A_{3}$ in inflammatory events: a required role in neutrophil migration across intestinal epithelia. Proc. Natl. Acad. Sci. USA 101, 7421-7426 (2004).

14. Siangjong, L. et al. Vascular hepoxilin and trioxilins mediate vasorelaxation through TP receptor inhibition in mouse arteries. Acta Physiol. (Oxf.). 219, 188-201 (2017).

15. Yu, Z., Schneider, C., Boeglin, W. E. \& Brash, A. R. Epidermal lipoxygenase products of the hepoxilin pathway selectively activate the nuclear receptor PPAR $\alpha$. Lipids 42, 491-497 (2007).

16. Vogan, C. L. et al. Hepoxilins and trioxilins in barnacles: an analysis of their potential roles in egg hatching and larval settlement. J. Exp. Biol. 206, 3219-3226 (2003).

17. Joo, Y. C. \& Oh, D. K. Lipoxygenases: potential starting biocatalysts for the synthesis of signaling compounds. Biotechnol. Adv. 30, 1524-1532 (2012).

18. Zou, J. et al. Structure of Aspergillus niger epoxide hydrolase at 1.8 A resolution: implications for the structure and function of the mammalian microsomal class of epoxide hydrolases. Structure 8, 111-122 (2000).

19. Steinreiber, A. \& Faber, K. Microbial epoxide hydrolases for preparative biotransformations. Curr. Opin. Biotechnol. 12, 552-558 (2001).

20. Fretland, A. J. \& Omiecinski, C. J. Epoxide hydrolase: biochemistry and molecular biology. Chem. Biol. Interact. 129, 41-59 (2000).

21. Pace-Asciak, C. R. \& Lee, W. S. Purification of hepoxilin epoxide hydrolase from rat liver. J. Biol. Chem. 264, 9310-9313 (1989).

22. Rapp, J. 12-lipoxygenases. Master's thesis, The University of Toledo (2006).

23. Thunnissen, M. M. G. M., Nordlund, P. \& Haeggstrom, J. Z. Crystal structure of human leukotriene $\mathrm{A}_{4}$ hydrolase, a bifunctional enzyme in inflammation. Nat. Struct. Biol. 8, 131-135 (2001).

24. Ortiz, M. I. et al. Isolation, identification and molecular docking as cyclooxygenase (COX) inhibitors of the main constituents of Matricaria chamomilla $L$. extract and its synergistic interaction with diclofenac on nociception and gastric damage in rats. Biomed. Pharmacother. 78, 248-256 (2016).

25. Inoue, T. et al. Mechanism of metal activation of human hematopoietic prostaglandin D synthase. Nat. Struct. Biol. 10, 291-296 (2003).

26. Tanaka, D. et al. A practical use of ligand efficiency indices out of the fragmentbased approach: Ligand efficiency-guided lead identification of soluble epoxide hydrolase inhibitors. J. Med. Chem. 54, 851-857 (2011).

27. Coffa, G. \& Brash, A. R. A single active site residue directs oxygenation stereospecificity in lipoxygenases: stereocontrol is linked to the position of oxygenation. Proc. Natl. Acad. Sci. USA 101, 15579-15584 (2004).

28. Wang, L. H. \& Kulmacz, R. J. Thromboxane synthase: structure and function of protein and gene. Prostaglandins Other Lipid Mediate. 68-9, 409-422 (2002).

29. Chen, X. S. \& Funk, C. D. Structure-function properties of human platelet 12lipoxygenase: chimeric enzyme and in vitro mutagenesis studies. FASEB J. 7, 694-701 (1993)

30. Pace-Asciak, C. R., Martin, J. M. \& Corey, E. J. Hepoxilins, potential endogenous mediators of insulin release. Prog. Lipid Res. 25, 625-628 (1986).

31. Pace-Asciak, C. R. Formation of hepoxilin $\mathrm{A}_{4}, \mathrm{~B}_{4}$ and the corresponding trioxilins from 12(S)-hydroperoxy-5,8,10,14,17-icosapentaenoic acid. Prostaglandins Leukot. Med. 22, 1-9 (1986).

32. Reynaud, D. \& Pace-Asciak, C. R. Docosahexaenoic acid causes accumulation of free arachidonic acid in rat pineal gland and hippocampus to form hepoxilins from both substrates. Biochim. Biophys. Acta 1346, 305-316 (1997).

33. Pfister, S. L. et al. Metabolism of 12-hydroperoxyeicosatetraenoic acid to vasodilatory trioxilin $C_{3}$ by rabbit aorta. BBA Gen. Subj. 1622, 6-13 (2003).

34. Atanasov, A. G. et al. Honokiol: a non-adipogenic PPARg agonist from nature. Biochim. Biophys. Acta 1830, 4813-4819 (2013).

35. Mosblech, A., Feussner, I. \& Heilmann, I. Oxylipins: structurally diverse metabolites from fatty acid oxidation. Plant. Physiol. Biochem. 47, 511-517 (2009).

36. Brash, A. R., Boeglin, W. E., Chang, M. S. \& Shieh, B. H. Purification and molecular cloning of an $8 R$-lipoxygenase from the coral Plexaura homomalla reveal the related primary structures of $R$ - and $S$-lipoxygenases. J. Biol. Chem. 271, 20949-20957 (1996).

37. Brodhun, F. et al. An iron 13S-lipoxygenase with an $\alpha$-linolenic acid specific hydroperoxidase activity from Fusarium oxysporum. PLoS ONE 8, e64919 (2013).

38. An, J. U., Kim, B. J., Hong, S. H. \& Oh, D. K. Characterization of an $\omega-6$ linoleate lipoxygenase from Burkholderia thailandensis and its application in the production of 13-hydroxyoctadecadienoic acid. Appl. Microbiol. Biotechnol. 99, 5487-5497 (2015).

39. Lang, I. et al. A lipoxygenase with linoleate diol synthase activity from Nostoc sp. PCC 7120. Biochem. J. 410, 347-357 (2008).
40. Gao, B. L., Boeglin, W. E. \& Brash, A. R. $\omega-3$ fatty acids are oxygenated at the n7 carbon by the lipoxygenase domain of a fusion protein in the cyanobacterium Acaryochloris marina. BBA Mol. Cell Biol. Lipids 1801, 58-63 (2010).

41. Vance, R. E. et al. The opportunistic pathogen Pseudomonas aeruginosa carries a secretable arachidonate 15-lipoxygenase. Proc. Natl. Acad. Sci. USA 101, 2135-2139 (2004).

42. Gregus, A. M. et al. Systematic analysis of rat 12/15-lipoxygenase enzymes reveals critical role for spinal eLOX3 hepoxilin synthase activity in inflammatory hyperalgesia. FASEB J. 27, 1939-1949 (2013).

43. Reynaud, D., Ali, M., Demin, P. \& Pace-Asciak, C. R. Formation of 14,15hepoxilins of the $A_{3}$ and $B_{3}$ series through a 15-lipoxygenase and hydroperoxide isomerase present in garlic roots. J. Biol. Chem. 274, 28213-28218 (1999).

44. Tsai, C. J., Li, W. F. \& Pan, B. S. Characterization and immobilization of marine algal 11-lipoxygenase from Ulva fasciata. J. Am. Oil. Chem. Soc. 85, 731-737 (2008).

45. Tzameli, I. et al. Regulated production of a peroxisome proliferator-activated receptor- $\gamma$ ligand during an early phase of adipocyte differentiation in 3T3-L1 adipocytes. J. Biol. Chem. 279, 36093-36102 (2004).

46. Cha, B. S. et al. Peroxisome proliferator-activated receptor (PPAR) $\gamma$ and retinoid X receptor (RXR) agonists have complementary effects on glucose and lipid metabolism in human skeletal muscle. Diabetologia 44, 444-452 (2001).

47. Song, Y. S. et al. 15-Hydroxyeicosatetraenoic acid inhibits phorbol-12myristate-13-acetate-induced MUC5AC expression in NCI-H292 respiratory epithelial cells. J. Microbiol. Biotechnol. 25, 589-597 (2015).

48. Napimoga, M. H. et al. Peroxisome proliferator-activated receptor-g ligand, 15 deoxy-delta12,14-prostaglandin J2, reduces neutrophil migration via a nitric oxide pathway. J. Immunol. 180, 609-617 (2008).

49. Sotiropoulos, K. B. et al. Adipose-specific effect of rosiglitazone on vascular permeability and protein kinase $C$ activation: novel mechanism for PPARg agonist's effects on edema and weight gain. FASEB J. 20, 1203-1205 (2006).

50. Taylor, B. K. et al. Peroxisome proliferator-activated receptor agonists inhibit inflammatory edema and hyperalgesia. Inflammation 26, 121-127 (2002).

51. Gruszka, A., Kunert-Radek, J. \& Pawlikowski, M. Rosiglitazone, PPAR $\gamma$ receptor ligand, decreases the viability of rat prolactin-secreting pituitary tumor cells in vitro. Neuro. Endocrinol. Lett. 26, 51-54 (2005).

52. Memon, R. A. et al. Up-regulation of peroxisome proliferator-activated receptors (PPAR- $\alpha$ ) and PPAR- $\gamma$ messenger ribonucleic acid expression in the liver in murine obesity: troglitazone induces expression of PPAR- $\gamma$-responsive adipose tissue-specific genes in the liver of obese diabetic mice. Endocrinology 141, 4021-4031 (2000).

53. Burstein, H. J. et al. Use of the peroxisome proliferator-activated receptor (PPAR) $\gamma$ ligand troglitazone as treatment for refractory breast cancer: a phase II study. Breast Cancer Res. Treat. 79, 391-397 (2003).

54. Capelli, D. et al. Structural basis for PPAR partial or full activation revealed by a novel ligand binding mode. Sci. Rep. 6, 34792 (2016).

55. Zoete, V., Grosdidier, A. \& Michielin, O. Peroxisome proliferator-activated receptor structures: ligand specificity, molecular switch and interactions with regulators. Biochim. Biophys. Acta 1771, 915-925 (2007).

56. Liberato, M. V. et al. Medium chain fatty acids are selective peroxisome proliferator activated receptor (PPAR) gamma activators and pan-PPAR partial agonists. PLoS ONE 7, e36297 (2012).

57. Kliewer, S. A. et al. Fatty acids and eicosanoids regulate gene expression through direct interactions with peroxisome proliferator-activated receptors $\alpha$ and $\gamma$. Proc. Natl. Acad. Sci. USA 94, 4318-4323 (1997).

58. Ma, J. J. et al. Establishment of a cell-based drug screening model for identifying agonists of human peroxisome proliferator-activated receptor gamma (PPAR $\gamma$ ). J. Pharm. Pharmacol. 64, 719-726 (2012).

59. Wu, G. et al. Pseudoginsenoside F11, a novel partial ppar gamma agonist, promotes adiponectin oligomerization and secretion in 3T3-L1 adipocytes. Ppar. Res. 2013, 701017 (2013).

60. Chana, R. S., Lewington, A. J. \& Brunskill, N. J. Differential effects of peroxisome proliferator activated receptor-gamma (PPAR gamma) ligands in proximal tubular cells: thiazolidinediones are partial PPAR gamma agonists. Kidney Int. 65, 2081-2090 (2004).

61. Yu, J. et al. Polypharmacology of $N^{6}$-(3-iodobenzyl)adenosine- $5^{\prime}-\mathrm{N}$ methyluronamide (IB-MECA) and related $\mathrm{A} 3$ adenosine receptor ligands: peroxisome proliferator activated receptor (PPAR) gamma partial agonist and PPARdelta antagonist activity suggests their antidiabetic potential. J. Med. Chem. 60, 7459-7475 (2017).

62. Camp, H. S. et al. Differential activation of peroxisome proliferator-activated receptor-gamma by troglitazone and rosiglitazone. Diabetes $49,539-547$ (2000). 
63. Andreou, A., Gobel, C., Hamberg, M. \& Feussner, I. A bisallylic minilipoxygenase from cyanobacterium Cyanothece sp. that has an iron as cofactor. J. Biol. Chem. 285, 14178-14186 (2010).

64. Nigam, S. et al. The rat leukocyte-type 12-lipoxygenase exhibits an intrinsic hepoxilin $\mathrm{A}_{3}$ synthase activity. J. Biol. Chem. 279, 29023-29030 (2004).

\section{Acknowledgements}

This study was funded by the Mid-Career Researcher Program, through the National Research Foundation grant funded by the Ministry of Science, ICT and Future Planning, Republic of Korea (No. 2016R1A2B3006881).

\section{Author contributions}

D.-K.O. supervised this study. J.-U.A. performed most experiments, including cloning protein expression, enzyme purification, and enzyme and cell reactions. Y.-S.S. carried out the transcriptional activity assay, and Y.-J.K. analysed the NMR data. J.-U.A., Y.-S.S., K.-R.K., D.-Y.Y., and D.-K.O. designed the experiments and contributed to data analysis. J.-U.A. gathered and organised the results. J.-U.A., Y.-S.S., K.-R.K., Y.-J.K., D.-Y.Y., and D.-K.O. wrote the manuscript.

\section{Additional information}

Supplementary Information accompanies this paper at https://doi.org/10.1038/s41467017-02543-8.

Competing interests: The authors declare no competing financial interests.

Reprints and permission information is available online at http://npg.nature.com/ reprintsandpermissions/

Publisher's note: Springer Nature remains neutral with regard to jurisdictional claims in published maps and institutional affiliations.

(c) (i) Open Access This article is licensed under a Creative Commons Attribution 4.0 International License, which permits use, sharing, adaptation, distribution and reproduction in any medium or format, as long as you give appropriate credit to the original author(s) and the source, provide a link to the Creative Commons license, and indicate if changes were made. The images or other third party material in this article are included in the article's Creative Commons license, unless indicated otherwise in a credit line to the material. If material is not included in the article's Creative Commons license and your intended use is not permitted by statutory regulation or exceeds the permitted use, you will need to obtain permission directly from the copyright holder. To view a copy of this license, visit http://creativecommons.org/ licenses/by/4.0/.

(C) The Author(s) 2018 